\title{
EVALUASI SISTEM INFORMASI PEMBAYARAN MENGUNAKAN FRAMEWORK COBIT 4.1
}

\author{
Faizal Gunawan ${ }^{1)}$; Sri Siswanti ${ }^{2)}$; Andriani Kusumaningrum ${ }^{3)}$ \\ ${ }^{1,3)}$ Program Studi Sistem Informasi, STMIK Sinar Nusantara Surakarta \\ ${ }^{2)}$ Program Studi Teknik Informatika, STMIK Sinar Nusantara Surakarta \\ ${ }^{2)}$ Program Studi Komputerisasi Akuntansi, STMIK Sinar Nusantara Surakarta \\ 1) faizal.wiryadarsya@gmail.com; ${ }^{2)}$ syswanty@sinus.ac.id; ${ }^{3)}$ andrianikkw@sinus.ac.id
}

\begin{abstract}
University of Tunas Pembangunan Surakarta is one of the universities in Surakarta. University of Tunas Pembangunan utilizes $I T$ in the utilization and management of its organizational processes, especially in payments using financial information systems. The focus of the problem by the payment service provider is the information system that has not been integrated with the bank, data input is still using proof of payment from the bank and then in the manual input by staff BAUK. Problems that occur are the strokes in inputting data, the number of queues during student activation, and the length of the flow during KRS activation. The purpose of the research is to find out what the maturity level value in the IT process has been applied at the Tunas Pembangunan University and provide recommendations that need to be improved. This research uses COBIT 4.1 Framework with DS1 and DS11 domain process. The degree of maturity to evaluate payment service providers for Financial Information Systems is at Level 3 (Process Defined). This is in accordance with the current state of financial information management. The expected maturity level in BAUK is 5 (Optimized) then from what it is and there should be a gap emerging then given recommendations to make improvements to the desired level of maturity achieved.

Keywords: Payment services, financial information system, COBIT 4.1, Domain DS1 dan DS11, Defined Process.
\end{abstract}

\section{PENDAHULUAN}

Universitas Tunas Pembangunan Surakarta merupakan salah satu Perguruan Tinggi yang ada di Surakarta. Saat ini Universitas Tunas Pembangunan Surakarta memiliki empat Fakultas dan delapan Program Studi Strata Satu. Universitas Tunas Pembangunan sudah memanfaatkan TI. dalam pemanfaatan dan pengelolaan proses organisasinya khususnya dibagian pembayaran menggunakanan sistem informasi keuangan. Hasil survei lapangan menunjukkan permasalahan yang dihadapi penyedia layanan pembayaran BAUK Universitas Tunas Pembangunan dalam layanan pembayaran adalah Pertama, proses organisasi yang ada pada penyedia layanan pembayaran pada Biro Administrasi Urusan Keuangan (BAUK) proses layanan pembayaran masih manual karena belum terintegrasi dengan pihak bank, penginputan data masih menggunakan bukti pembayaran dari bank kemudian di input manual oleh staff BAUK yang mengakibatkan kesalahan dalam penginputan data, banyaknya antrian saat aktivasi mahasiswa, dan panjang nya alur saat aktivasi KRS. Kedua, Pada pengelolaan data masih perlu penambahan khususnya dalam akuntansi data pembayaran belum ada sub menu untuk mengelola data pembayaran mahasiswa hanya dapat menampilkan data pembayaran saja untuk pengelolaan akuntansi data mahasiswa masih menggunakan software excel untuk pembuatan laporan.

Berdasarkan masalah diatas tujuan TI yang paling sesuai adalah tentang bagaimana Universitas Tunas Pembangunan merespon terhadap kebutuhan bisnis yang selaras dengan strategi bisnis serta optimasian dari penggunaan informasi. Evaluasi menggunakan subdomain dari DS (Delivery and Support) yaitu DS1 dan DS11 tujuannya untuk mengetahui berapa nilai tingkat kematangan pada proses $\mathrm{TI}$ yang telah diterapkan di Universitas Tunas Pembangunan dan memberikan rekomendasi yang perlu diperbaiki.

Pada Proses DS11 Manage Data (mengelola data), fokus utama proses DS11 adalah memelihara kelengkapan, keakuratan, ketersediaan, dan perlindungan data. Agar beberapa indikator yang digunakan untuk mengukur pencapaian proses DS11 adalah: 
Kepuasan pemakai terhadap ketersediaan data, Presentasi keberhasilan pemulihan data, Jumlah insiden ketika data yang sensitif dapat diperoleh kembali setelah media dimusnahkan [1]

Penelitian Wire Bagye (2016), guna menyusun rekomendasi, dilakukan analisis kepatuhan pada tabel activity COBIT 4.1. yang digunakan untuk menaikkan satu tingkat kematangan tata kelola saat ini pihak penyelenggara harus melaksanakan rekomendasi activity. Analisis tingkat kematangan Tata kelola $\mathrm{TI}$ pada sistem informasi akademik STMIK Lombok merupakan implementasi prosedur pengukuran tingkat kematangan untuk mendapatkan nilai tingkat kematangan kondisi saat ini pada bisnis, tujuannya untuk meningkatkan orientasi pelanggan dan layanan berdsarkan framework COBIT 4.1. Penelitian ini menghasilkan nilai tingkat kematangan pengelolaan tata kelola IT Sistem Informasi Akademik kondisi saat ini. Nilai tingkat kematangan ini sebagai alat ukur keselarasan implementasi Sistem Informasi Akademik terhadap upaya Meningkatkan Orientasi Pelanggan Dan Layanan. Berdasarkan hasil perhitungan tingkat kematangan Implementasi Sistem Informasi Akademik STMIK Lombok berada pada tingkat 1 (sangat tidak baik). [2]

\section{TINJAUAN PUSTAKA}

Pada COBIT 4.1 Process Assessment Model, ketercapaian suatu level diukur berdasarkan ketercapaian atribut yang ada pada level tersebut dan level sebelumnya. Berdasarkan aturan pada ISO/IEC 15504, ketercapaian level 2 dapat diukur apabila level 1 telah terpenuhi dan atribut pada level 1 telah mencapai rating "Fully Achieved". Ketercapaian level 3 dapat diukur bila level 2 terpenuhi dan semua atribut pada level 2 telah mencapai rating "Fully Achieved". Hal ini berlaku pula untuk level-level selanjutnya. Hasil pengukuran STKIP Garut yang dilakukan untuk level 1 sampai dengan level 5 pada dengan menggunakan COBIT 4.1 Process Assessment Model. Level 1 memiliki ketercapaian sebesar $60 \%$ yang berarti skala ketercapaian diposisi Largely Achieved, Level 2 memiliki ketercapaian sebesar 59\% yang berarti skala ketercapaian diposisi Largely Achieved, Level 3 memiliki ketercapaian sebesar $60 \%$ yang berarti skala ketercapaian diposisi Largely Achieved, Level 4 memiliki ketercapaian sebesar $61 \%$ yang berarti skala ketercapaian diposisi Largely Achieved, Level 5 memiliki ketercapaian sebesar $60 \%$ yang berarti skala ketercapaian diposisi Largely Achieved. [3].

Penelitian yang dilakukan Megawati, audit sistem informasi manajemen SMK Labor Binaan FKIP UNRI ini menggunakan framework COBIT 4.1 domain Delivery and Support (DS) terutama pada proses antara lain: menentukan dan Mengatur tingkat layanan (DS1), memastikan keamanan system(DS5), Mengelola data (DS11), Mengatur lingkungan fisik (DS12), dan mengelola operasi (DS13). Hasil audit menunjukkan tingkat kematangan proses level 2 yang berarti terjadi perulangan proses. Sedangkan target yang ingin dicapai yaitu level 3 setiap proses telah diatur dan di dokumentasikan dengan baik. Untuk mencapai level tersebut maka diberikan rekomendasi perbaikan proses.[4]

Penelitian Bani Saad, STIE Indonesia Banking School perlu menerapkan model IT Governance dari CobiT beserta alat ukurnya Capability Maturity Model karena sudah banyak diterapkan di berbagai belahan dunia dan memiliki standar internasional. Berdasarkan hasil yang diperoleh dari Capability Maturity Model untuk domain Plan \& Organise memperoleh nilai 2.72 , sehingga perlu ditingkatkan lagi mendekati 4, Acquire \& Implement memperoleh nilai 2.57 sehingga perlu ditingkatkan lagi mendekati 4, Deliver \& Support memperoleh nilai 2.9 sehingga perlu ditingkatkan lagi mendekati 4, Monitor \& Evaluate memperoleh nilai 2.32 sehingga perlu ditingkatkan lagi mendekati 4. Total nilai rata-rata keseluruhan domain CobiT STIE Indonesia Banking School adalah 2.71, sehingga perlu ditingkatkan lagi menjadi 4. [5]

Berdasarkan penelitian audit yang telah dilakukan, maka dapat diambil kesimpulan bahwasannya proses audit sistem informasi terhadap PT. IMI dilakukan menggunakan standart framework Cobit 4.1 khusus pada domain deliver support (DS) khusus pada proses DS 1, DS2, DS 3, DS 4, DS 5, DS 7, DS 9, DS 10, DS 11, DS 12 dan hasil tingkat kematangan ( maturity level ) pada implementasi sistem administrasi logistic khusus pada domain DS yang berada pada level 4 yang berarti sudah terukur dan terintegrasi antar proses yang berlangsung. Analisa Gap antara kondisi yang diharapkan dengan kondisi saat ini rata-rata adalah 0,50 dengan rekomendasi pengecekan berkala terhadap data transaksi yang terjadi pada 
setiap bagian untuk meminimalisir resiko atau masalah yang akan muncul dikemudian hari dan peningkatan keamanan sistem mengingat data adalah salah satu asset perusahaan yang sangat berharga. [6]

Penelitian Noor Azizah, Proses audit sistem informasi terhadap e- learning yang berjalan di UNISNU Jepara dilakukan menggunakan standar framework COBIT 4.1 khusus pada domain deliver and support (DS) khusus pada proses DS 3, DS 5, DS 7, DS 9, DS 10, DS 11, DS 13. 2) Hasil tingkat kematangan (maturity level) pada implementasi e-learning UNISNU Jepara khusus pada domain DS berada pada level 4 yang berarti sudah terukur dan terintegrasi antar proses yang berlangsung Analisa GAP antara kondisi yang diharapkan dengan kondisi saat ini rata-rata adalah 0,6 dengan rekomendasi perbaikannya ditekankan pada peningkatan keamanan sistem dan memberikan pelatihan dan sosialisasi yang lebih intens agar keberlangsungan e-learning dapat maksimal. [7]

\section{METODE PENELITIAN}

\subsection{Metode Pengumpulan Data}

\section{Observasi}

Metode observasi adalah melakukan pengamatan secara langsung terhadap kegiatan yang sedang berlangsung. Observasi ini diakukan untuk memperoleh data proses sistem berjalan, proses pembayaran mahasiswa, model informasi dan pengelolaan data.

\section{Wawancara}

Wawancara dilakukan kepada staff bagian pembayaran di Universitas Tunas Pembangunan dengan mengajukan beberapa pertanyaan yang berkaitan dengan sistem informasi keuangan bagian pembayaran.

\section{Studi Pustaka}

Studi pustaka adalah mengambil data dari bahan pustaka yang berkaitan dengan topik sistem informasi keuangan, analis sistem informasi, dan juga sebagai data pendukung dalan penulisan penelitian.

\section{Kuisioner atau Angket}

Kuisioner dilakukan dengan cara menyebarkan daftar pertanyan secara tertulis diajukan ke staff bagian keuangan dan di sebar disebagian mahasiswa. Setelah hasil kuisioner diperoleh kemudian melakukan analisis dan pengolahan data yang dilakukan

\section{HASIL DAN PEMBAHASAN}

\subsection{Analisa Data}

Pembuatan kuisioner ini bertujuan untuk mendapatkan gambaran mengenai sistem lebih cepat dan menyeluruh dalam bentuk angket pertanyaan kepada responden terpilih. Dalam kuisioner ini terdapat 72 pertanyaan yang disesuaikan dengan 6 prinsip atribut Awareness and Communication (AC), Policies, Standarts, and Procedure (PSP), Tools and Automation (TA), Skill and Expertise (SE), Responsibiities and Accountabilies (RA), Goals Setting and Measurement (GSM).

Tabel 1. RACl

\begin{tabular}{|l|l|c|}
\hline Struktur RACI & Struktur jabatan & Jumlah \\
\hline Responsible & $\begin{array}{l}\text { Staff Pengelola } \\
\text { sistem }\end{array}$ & 1 \\
\hline Responsible & $\begin{array}{l}\text { Staff bagian } \\
\text { pembayaran }\end{array}$ & 5 \\
\hline Accountable & Kepala BAUK & 1 \\
\hline Consulted & Wakil Rektor 2 & 1 \\
\hline Informed & Mahasiswa & 95 \\
\hline
\end{tabular}

\subsection{Tingkat Kematangan saat ini (as-is)}

Analisis tingkat kematangan penggunaan sistem informasi keuangan perlu dilakukan dengan menyebarkan kuesioner sesuai dengan standar COBIT 4.1 dan mengacu pada 6 atribut COBIT 4.1 yaitu (Kepedulian dan komunikasi (awareness and communication), Kebijakan, standar dan prosedur (polices, standard and procedures), Perangkat bantu dan otomatisasi (tools and automation), Keterampilan dan keahlian (skills and expertise), Pertanggungjawaban external dan internal (responsibility and accountability), Penetapan tujuan dan pengukuran (goal setting and measurement).

\subsection{Tingkat Kematangan Yang Diharapkan (to-be)}

Target tingkat harapan penggunaan sistem adalah kondisi ideal tingkat kematangan proses yang diharapkan dari penyedia layanan pembayaran BAUK, yang akan menjadi acuan dalam model tata kelola teknologi informasi yang akan dikembangkan. Target tingkat kematangan proses teknologi informasi dapat ditentukan dengan melihat 
lingkungan internal staff pegawai dan tingginya ekspektasi jajaran manajemen BAUK terhadap proses teknologi informasi COBIT 4.1 yang diterapkan. Dengan mempertimbangkan beberapa faktor diatas, untuk domain, Deliver and Support 1 dan Deliver and Support 11, maka dapat diambil kesimpulan bahwa tingkat kematangan yang diharapkan yang akan menjadi acuan dalam model tata kelola teknologi informasi yang akan dikembangkan adalah pada skala 5 yaitu Optimized.

\subsection{Analisis Kesenjangan \\ Kematangan (Gap Analysis)}

Tingkat

Dapat lihat bahwa level sekarang berada pada level 3 dan level yang diharapkan berada pada level 5 . Kondisi tersebut menimbulkan kesenjangan (gap) sebesar 2. Maka untuk mengupayakan level sesuai dengan yang diharapkan dapat diatasi dengan merumuskan rekomendasi.

Tabel 1. Perbandingan Tingkat Kematangan DS 1 Saat ini (as-is) dan Tingkat Kematangan yang Diharapkan (to-be)

\begin{tabular}{|l|c|c|c|c|}
\hline CO & as-is & $M L$ & to-be & gap \\
\hline DS1.1 & 2,6926 & 3 & 5 & 2 \\
\hline DS1.2 & 2,7638 & 3 & 5 & 2 \\
\hline DS1.3 & 2,7330 & 3 & 5 & 2 \\
\hline DS1.4 & 2,7864 & 3 & 5 & 2 \\
\hline DS1.5 & 2,7476 & 3 & 5 & 2 \\
\hline DS1.6 & 2,7945 & 3 & 5 & 2 \\
\hline
\end{tabular}

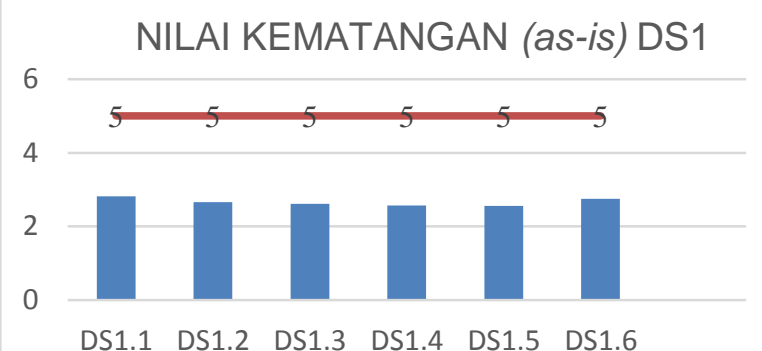

$\begin{array}{llllll}\text { DS1.1 } & \text { DS1.2 } & \text { DS1.3 } & \text { DS1.4 } & \text { DS1.5 } & \text { DS1.6 }\end{array}$

as-is to-be

Gambar 1 Rata-rata Nilai Kematangan DS1 Saat ini (as-is)

Tabel 2. Perbandingan Tingkat Kematangan DS 11 Saat ini (as-is) dan Tingkat Kematangan yang Diharapkan (to-be)

\begin{tabular}{|c|c|c|c|c|}
\hline CO & as-is & $M L$ & to-be & gap \\
\hline DS11.1 & 2,8236 & 3 & 5 & 2 \\
\hline DS11.2 & 2,6553 & 3 & 5 & 2 \\
\hline DS11.3 & 2,6165 & 3 & 5 & 2 \\
\hline DS11.4 & 2,5647 & 3 & 5 & 2 \\
\hline DS11.5 & 2,5583 & 3 & 5 & 2 \\
\hline DS11.6 & 2,7524 & 3 & 5 & 2 \\
\hline
\end{tabular}

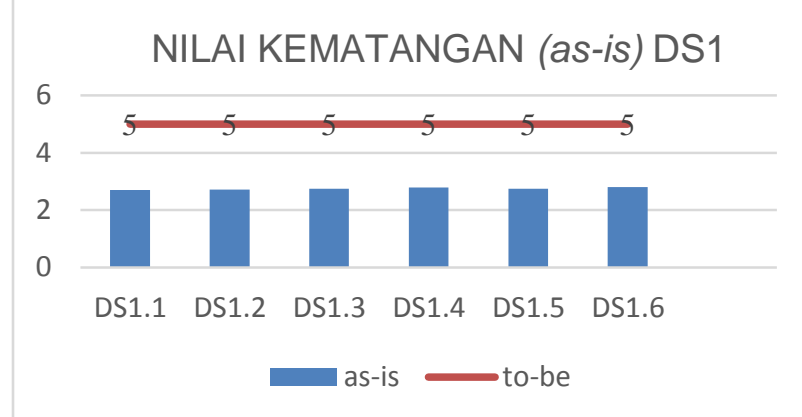

Gambar 2 Rata-rata Nilai Kematangan DS1 Saat ini (as-is)

\subsection{Rekomendasi}

Setelah melakukan analisis tingkat kesenjangan (gap) maka diperlukan penyesuaian untuk menutup gap yang muncul agar dapat mencapai tingkat kematangan yang diinginkan (Target Maturity Level). Untuk menutup kesenjangan tersebut diperlukan rekomendasi tindakan perbaikan. Rekomendasi memberikan perbaikan dan penyempurnaan yang harus diusahakan secara terus menerus dan berkelanjutan agar sistem dapat menjadi lebih baik. Dengan proses perbaikan secara bertahap diharapkan proses pematangan dapat dilaksanakan secara efektif.

\section{a. Rekomendasi Perbaikan Domain Deliver \& Support 1}

1. Diselenggarakan forum yang teragenda untuk dapat mengkomunikasikan permasalahan terkait dengan layanan pembayaran dari sistem dan pada setiap tingkat layanan pembayaran untuk menyelaraskan kebutuhan pembayaran dan kemampuan TI.

2. Kebijakan dan prosedur pada penyedia layanan pembayaran setiap tingkat layanan pembayaran harus sudah terintegrasi, sehingga mahasiswa tidak perlu berlama-lama untuk melakukan pembayaran dan aktivasi KRS.

3. Pengintegrasian semua sistem informasi yang ada pada setiap tingkat layanan pembayaran, baik secara proses maupun data yang digunakan. Agar semua proses bisnis dengan mudah dijalankan.

4. Pelatihan yang disediakan oleh pihak kampus terhadap staff BAUK sebagai pengguna sistem informasi pembayaran pada setiap tingkat layanan pembayaran, harus sudah dilakukan secara formal dan terprogram. 
5. Setiap pengguna sistem informasi pembayaran diharuskan bertanggung jawab atas proses layanan pembayaran pada sesuai tingkatannya. Apabila terjadi kesalahan penggunaan atau data, maka pemilik akun yang bersangkutan akan diminta pertanggung jawabannya. Sehingga kesalahan ini tidak selalu ditanggung oleh semua staff layanan pembayaran

6. Dilakukan pengukuran terhadap sistem aplikasi pada setiap tingkat layanan pembayaran. Hal tersebut bertujuan untuk mengetahui sejauh mana sistem aplikasi sudah mendukung layanan pembayaran yang diberikan terhadap mahasiswa.

\section{b. Rekomendasi Perbaikan Domain Deliver \\ \& Support 11}

1. Adanya forum diskusi secara rutin untuk mencari solusi dari masalah yang sedang berkembang dalam pengelolaan data dan penambahan sub menu sistem akuntansi data pembayaran untuk lebih mempermudah pengelolaan data pembayaran di penyedia layanan pembayaran BAUK.

2. Adanya prosedur yang jelas untuk pengaturan penyimpanan data agar data yang sensitive tidak sampai ke pihak yang tidak berwenang. Hal ini menyangkut mengenai kebutuhan keamanan untuk manajemen data agar data yang disimpan aman. Prosedur-prosedur yang ada kemudian disosialisasikan kepada seluruh staff untuk kemudian dipatuhi dan dijalankan sesuai yang ada pada prosedur.

3. Tools yang digunakan merupakan tools yang terbaru dan terintegrasi dengan tools lainnya untuk menunjang aktivitas pengelolaan data.

4. Pelatihan resmi dilakukan secara rutin, terencana, dan sesuai kebutuhan karyawan dalam pengelolaan data kemudian diadakan sertifikasi karyawan dalam hal pengelolaan data. Knowledge sharing dilakukan untuk meningkatkan kemampuan karyawan. Knowledge sharing dapat berupa seminar atau forum diskusi.

5. Pihak Kampus membuat kebijakan yang menegaskan bahwa pemilik proses yang berkaitan dengan pengelolaan data bisa membuat keputusan dan melakukan tindakan yang diperlukan agar masalah yang sedang dihadapi bisa langsung dipecahkan tanpa menunggu dari manajemen atas.

6. Adanya audit internal untuk perbaikan kualitas pada proses pengelolaan data. Untuk selama ini audit dilakukan oleh pihak Yayasan (eksternal).

\section{PENUTUP}

\subsection{Kesimpulan}

Berdasarkan dari hasil penelitian yang telah dilakukan mengenai evaluasi sistem informasi pembayaran mengunakan framework COBIT 4.1 (Studi Kasus : Universitas Tunas Pembangunan), maka penulis mengambil kesimpulan hasil penelitian yang diperoleh, maka tingkat kematangan per-domain dalam evaluasi sistem informasi pembayaran seperti pada Tabel 3.

Tabel 3 Tingkat Kematangan Per Domain

\begin{tabular}{|l|l|}
\hline \multicolumn{1}{|c|}{ Domain } & Current Maturity Level \\
\hline$D S 1$ & 2,7529 \\
\hline$D S 11$ & 2,6618 \\
\hline
\end{tabular}

1. Pada Domain Deliver \& Support 1, diperoleh hasil perhitungan kematangan saat ini sebesar 2,7529 dengan kondisi Define Process. Dari hasil penelitian ditunjukkan bahwa pengukuran tingkat kepuasan pelayanan di BAUK Universitas Tunas Pembangunan dilakukan melalui kuesioner, sudah ada standar baku pengelolaan layanan pembayaran walaupun belum terdapat pengawasan dan pengendalian dalam pelaksanaannya.

2. Pada Domain Deliver \& Support 1, diperoleh hasil perhitungan kematangan saat ini sebesar 2,6618 dengan kondisi Define Proces. Bagian BAUK sudah mengimplementasikan proses pengelolaan data pembayaran namun kurangnya tools yang tersedia membuat pengelolaan data kurang maksimal.

\subsection{Saran}

Saran untuk hasil penelitian mengenai evaluasi sistem informasi pembayaran mengunakan framework COBIT 4.1 dapat diambil saran sebagai berikut:

1. Untuk kedepannya sebaiknya dilakukan evaluasi pada semua domain dan sehingga semua modul atau semua kinerja sistem bisa dilihat kelemahan dan kekurangan pada sistem tersebut. 
2. Evaluasi yang dilakukan pada penelitian ini masih berupa analisis data dan aplikasi sederhana untuk menghitung kematangan. Maka dari itu untuk penelitian kedepannya dengan mempertimbangkan nilai guna. akan lebih baik membuat program aplikasi berupa pengolahan data kuesioner dan pengolahan hasil data untuk menentukan nilai kematangan yang ada pada standar COBIT 4.1

\section{DAFTAR PUSTAKA}

[1] L. Nilawati, "Audit TI Perusahaan Konsultan Properti Untuk Evaluasi Pengelolaan data (DS11)," J. Inform., vol. 5, no. 1, pp. 119-127, 2018.

[2] W. Bagye, "Analisis Tingkat Kematangan Sistem Informasi Akademik Menggunakan Framework COBIT 4.1 (Studi Kasus: STMIK Lombok)," J. Speed - Sentra Penelit. Eng. dan Edukasi, vol. 8, no. 1, pp. 1-7, 2016.

[3] S. Kasus, S. Garut, D. Nurdiana, and A. Suryadi, "Audit Sistem Informasi untuk Meningkatkan Kapabilitas Proses Pada Sistem Informasi Akademik di Perguruan Tinggi menggunakan Cobit 4 . 1 Berdasarkan ISO / IEC 15504," vol. 17, no. 1, pp. 21-29, 2018.

[4] Megawati, "Audit Sistem Informasi Manajemen Sekolah Menggunakan Framework Cobit 4.1 Studi Kasus pada SMK Labor Binaan FKIP UNRI," J. Sist. Inf., vol. 6, no. 2, pp. 689-700, 2014.

[5] B. Saad, "Analisis Implementasi Cobit 4.1 Pada Stie Indonesia Banking School Serta Dampaknya Terhadap Focus It Governance," vol. 12, no. 1, pp. 72-87, 2015.

[6] I. D. Lesmono and D. Erica, "Tata Kelola Teknologi Informasi Dengan Metode Cobit 4 . 1 ( Studi Kasus: PT . IMI )," vol. 10, no. 1, 2018.

[7] N. Azizah, "Audit Sistem Informasi Menggunakan Framework COBIT 4.1 Pada E-Learning Unisnu Jepara," J. SIMETRIS, vol. 8, no. 1, pp. 377-382, 2017. 